\title{
Comparison of Real time PCR and Conventional PCR for Detection of HLA-B27 in Suspected Ankylosing Spondylitis Patients
}

\author{
Jaspreet Kaur ${ }^{1}$, Jaswinder Singh ${ }^{2^{*}}$ \\ ${ }^{1}$ Senior Research Associate, Department of Biochemistry, Shri Ram Murti Smarak Institute of Medical Sciences, Bareilly, \\ U.P., India \\ ${ }^{2}$ Associate Professor, Department of Forensic Medicine and Toxicology, Shri Ram Murti Smarak Institute of Medical \\ Sciences, Bareilly, U.P., India
}

*Address for Correspondence: Dr. Jaswinder Singh, Associate Professor, Department of Forensic Medicine and Toxicology, Shri Ram Murti Smarak Institute of Medical Sciences, Bareilly-243202, U.P., India

E-mail: drjasvinder2013@gmail.com

Received: 08 Dec 2018/ Revised: 14 Mar 2019/ Accepted: 16 Jun 2019

\begin{abstract}
Background: Human leukocyte antigen B27 (HLA-B27) is a major histocompatibility complex (MHC) class 1 molecule that is strongly associated with the chronic inflammatory disease ankylosing spondylitis (AS). The aim of the present study was to evaluate the utility of real time PCR over conventional PCR to find out the involvement of HLA-B27 in relation to age and sex in symptomatic suspected patients.

Methods: The present cross-sectional study was conducted on the 320 suspected AS patients. Blood samples from patients were processed for PCR and real time PCR using HLA-B27 as a gene target.

Results: Out of 320 samples, $153(48 \%)$ and 163 (51\%) patients were found to be HLA-B27 positive in PCR and real time PCR respectively. Out of 153 and 163 positive samples, the positivity rate was maximum i.e. 59\% and $61 \%$ in the patients of $16-30$ years of age in PCR and real time PCR respectively. Furthermore, in terms of gender wise variation, 115 (75\%) and $126(77 \%)$ were male and remaining $38(25 \%)$ and $37(23 \%)$ were female in PCR and real time PCR respectively. Our data revealed sensitivity and specificity of real time PCR for HLA-B27 positive cases were $100 \%$ (95\% Cl: $89.11-100 \%$ with p-value 0.002$)$ and $94 \%$ (95\% Cl: 73.05-91.21\% with p-value 0.012 ) respectively. The PPV was $93.87 \%$ (95\% Cl: $73.01-105.36 \%$ with p-value 0.015$)$ and NPV was $100 \%$ (95\% Cl: 83.19 - 111.03\% with p-value 0.101).

Conclusion: It could be concluded that the real time PCR test is a fast, accurate and sensitive method for the diagnosis of AS.
\end{abstract}

Key-words: Ankylosing spondylitis, Human leukocyte antigen, HLA-B27, Real time PCR, Spondyloarthropathies

\section{INTRODUCTION}

The human leukocyte antigen system is a gene complex encoding the major histocompatibility complex proteins in humans. These cell-surface proteins are responsible for the regulation of the immune system. Although HLA molecules are best known for their role in transplantation, certain HLA molecules are associated

\section{How to cite this article}

Kaur J, Singh J. Comparison of Real time PCR and Conventional PCR for Detection of HLA-B27 in Suspected Ankylosing Spondylitis Patients. SSR Inst. Int. J. Life Sci., 2019; 5(4): 2355-2360.

\begin{tabular}{|l|l|}
\hline & Access this article online \\
& https://iijls.com/
\end{tabular}

with specific diseases. HLA-B27 (subtypes B*2701-2759) is an MHC class I surface antigen encoded by $B$ locus in the MHC on the short (p) arm of chromosome no. 6 and presents antigenic peptides (derived from self and nonself antigens) to T cells ${ }^{[1]}$. MHC class I molecules are cellsurface glycoproteins that are expressed on most nucleated human cells and platelets. The presence of HLA-B27 antigen is strongly associated with a number of rheumatic diseases, including AS, Reiter's syndrome, acute anterior uveitis, and inflammatory bowel disease (IBD) ${ }^{[2]}$. AS is a chronic inflammatory disorder of unknown cause that primarily affects the axial skeleton; peripheral joints and extra-articular structures may also be involved. AS affects men and women; the male to female prevalence was approximately 3:1. AS is a type of spondyloarthropathy $(\mathrm{SpA})$ that often starts in the late 
teens and early 20s but may also present earlier in childhood or at an older age ${ }^{[3]}$. Today the exact cause of AS is not known but the gene for HLA-B27 is present in $90 \%$ of all patients with AS and $50-75 \%$ of patients with other $\mathrm{SpA}$ diseases and therefore it is considered as a contributing factor. Studies on mice and rats using HLAB27 as a transgene developed ankylosing enthesopathy and rats having high copy number of HLAB*2705 developed axial and peripheral arthritis, gut inflammation, and lesions on the skin showed strong evidence of the involvement of HLA-B27 in AS ${ }^{[4,5]}$. The association with B27 is independent of disease severity. AS shares many features with several other arthritis conditions, such as psoriatic arthritis, reactive arthritis, and arthritis associated with Crohn's disease and ulcerative colitis. Each of these arthritic conditions can cause disease and inflammation in the spine, other joints, eyes, skin, mouth, and various organs ${ }^{[6]}$. Mostly HLA-B27 testing is performed with surface antigen tests. Two commercially available antibodies are commonly used. The cross-reactivity of these antibodies can compromise the accuracy of the results generated in the antigen assays ${ }^{[7]}$. Although the conventional PCR technology was a rapid and sensitive method for the diagnosis of $A S^{[8,9]}$. The main drawback was that its time taking and visualization was achieved only after electrophoresis and staining with ethidium bromide (a fluorescent DNA intercalating dye) and viewing the gel under UV light. The aim of the present study was to evaluated the utility of fluorogenic real time qualitative PCR over conventional PCR to detect the presence of the B*27 genotype by amplifying a region between primer sets and a specific dual labeled hydrolysis probe that recognized only $B * 27$ specific sequences. The advantages of this method were that primers and probes provide specificity to the reaction products and allow immediate visualization. The analytical capacity of this technique was much greater than the allele specific PCR and allowed for near complete automation.

\section{MATERIALS AND METHODS}

Study specimens- The present cross-sectional study was conducted on the 320 suspected AS patients attending the out and indoor patient departments (Medicine, Paediatrics, Orthopedics, and General Surgery) of Shri Ram Murti Smarak Institute of Medical Sciences (SRMS IMS), Bhojipura, Bareilly, India from Aug 2015 to Apr 2019. Two milliliters of blood was collected in a BD
Vacutainer $^{\circledR}$ (Cat. No. 367841) from each patient and transported at $4^{\circ} \mathrm{C}$ to the Central Research Laboratory of the Department of Biochemistry for further processing. Written consent was obtained from each patient for the present study. The clinical specimens used in this study were collected from patients of all age group and both sexes with suspected AS on the basis of clinical criteria or to rule out AS. The clinical criteria used was that the patients having low back pain and stiffness for more than 3 months, limitation of motion of the lumbar spine in both the sagittal and frontal planes and limitation of chest expansion relative to normal values corrected for age and sex. All procedures performed in studies involving human participants were in accordance with the ethical standards of the institute.

Nucleic Acid extraction- DNA was isolated from EDTA whole blood samples from 320 consecutive samples sent for HLA-B27 testing at our laboratory using QIAamp DNA Blood Mini Kit (Qiagen Inc., Valencia, CA, USA) (Cat no. 51304) as per manufacturer's instructions. The final DNA concentration was approximately $20 \mathrm{ng} / \mu \mathrm{l}$ and quantified by absorbance at $A_{260}$ for dilution experiments. A $5 \mu$ l aliquot of DNA was used for each PCR reaction, and therefore approximately $100 \mathrm{ng}$ of each sample was used, although there was considerable variation.

Conventional PCR- The PCR was performed in a total volume of $25 \mu \mathrm{l}$ containing $2.5 \mu \mathrm{l}$ of $10 \mathrm{x}$ reaction buffer HiBufferA with $2.5 \mathrm{mM} \mathrm{MgCl}_{2}, 2.5 \mu \mathrm{l}$ of $2.5 \mathrm{mM}$ dNTP's, $1 U$ HotStart Taq DNA polymerase ${ }^{[10]}$. The primer concentration was $1 \mu \mathrm{l}(1 \mu \mathrm{mol} / \mu \mathrm{l})$ in total, $0.5 \mu \mathrm{l}$ of the HLA-B27 specific primers (5' primer, B27ex294F: 5'CTACGTGGACGACACGCT-3'; 3' primer, B27ex2199RC: 5'AGTCTGTGCCTTGG CCTTGC-3') and $0.5 \mu \mathrm{l}$ of the human growth hormone $(\mathrm{HGH})$ specific primers $\mathrm{HGHI}$ (5'CAGTGCCTTCCCAACCATTCCCTTA-3') and HGH2 (5'ATCCACTCACGGATTTCTGTTGTGTTTC-3'). One cycle of denaturation at $96^{\circ} \mathrm{C}$ for 4 minutes was followed by 40 cycles at $96^{\circ} \mathrm{C}$ for $30 \mathrm{sec}$., $58^{\circ} \mathrm{C}$ for $30 \mathrm{sec}$., $72^{\circ} \mathrm{C}$ for 30 sec. followed by a final extension at $72^{\circ} \mathrm{C}$ for 5 minutes. Amplified products were visualized under UV light after electrophoresis on a $2 \%$ agarose gel and staining with ethidium bromide. Samples which had amplified products measuring $141 \mathrm{bp}$ bands for HLA-B27 were considered positive. Internal control produces a $437 \mathrm{bp}$ band, which must be present to validate the assay. 
Real time PCR- Real time PCR amplification for HLA-B27 was performed using the 3B HLA-B27 detection kit (3B BlackBio Biotech India Ltd) (Cat no. 3B247), in accordance with the manufacturer's protocol in a CFX96 ${ }^{\mathrm{TM}}$ real time system (BIO-RAD). This qualitative real time PCR test kit was based on the amplification of the allelic gene region by primer and probes specific for HLA-B27 with a sensitivity of $\geq 10$ copies in every microliter of sample. The probe contains a fluorescent dye molecule on its $5^{\prime}$ end and a quencher molecule on its 3 ' end. The probe hybridizes with one of the chains of the amplified fragment. During the synthesis of a complementary chain, Taq DNA polymerase, which possesses 5'-3' exonuclease activity cleaves the probe. As a result, the fluorescent dye and quencher dye were separated, and the total fluorescence of reaction volume increased in direct proportion to the number of amplicon copies synthesized during PCR. In this kit, there were two independent reactions running in parallel in each tube: the first detects HLA-B27 (FAM channel at $520 \mathrm{~nm}$ ) and second detects internal control (HEX channel at $556 \mathrm{~nm}$ ), which allows excluding unreliable results. The cycling conditions were 10 minutes at $95^{\circ} \mathrm{C}$ and 40 cycles of 15 seconds at $95^{\circ} \mathrm{C}, 60$ seconds at $60^{\circ} \mathrm{C}$ (single acquisition of fluorescence signals). The fluorescent signal was measured in each cycle of reaction, and the cycle threshold value $\left(C_{t}\right)$ was determined from the obtained curve. The $C_{t}$ was proportional to the initial number of DNA copies in a sample and its value allows qualitative comparisons of analyzed and control samples.

Quality control- Reagents were aliquoted and used only once for every reaction. Sterile microfuge tubes and PCR tubes were used for the PCR assay. Reagent preparation, DNA extraction, amplification, and detection were performed in separate rooms to avoid crosscontamination of amplicons. The positive control was included in each test and distilled water was included as a negative control.

Statistical Analysis- Data were analyzed using SPSS 18.0 (Statistical Package for the Social Sciences, Chicago, IL, USA) for Windows. Performance of PCR-based NAAT (Nucleic Acid Amplification Test) was reported in terms of sensitivity and specificity at $95 \%$ confidence interval along with their $p$-values. $p<0.05$ was considered statistically significant.

\section{RESULTS}

DNA was extracted from 320 samples and amplification was done using allele-specific conventional PCR ${ }^{[10]}$. Briefly, conventional PCR amplifies a 141bp band from exon 2 of the HLA-B27 family. Internal control primers specific for the HGH produces a 437bp band which must be present to validate the assay. In real time PCR, the fluorescent signal was generated from an oligonucleotide probe (fluorescent reporter dye probe) specifically used for HLA-B27 gene sequence. The appearance of amplification signal in real time PCR indicated the presence of HLA-B27 gene along with amplification signal of internal control, which was used for the validation of the result as it was present in the normal population as well as in patients (Fig. 1).

Out of 320 samples collected for the proposed study, 153 (48\%) patients were found to be HLA-B27 positive while remaining 167 (52\%) were negative in PCR. In real time PCR 163 (51\%) patients were found to be HLA-B27 positive, while remaining 157 (49\%) were negative. When samples were analyzed in terms of age groups, it was found that out of 153 PCR positive samples, the positivity rate was maximum i.e. $59 \%$ and $57 \%$ in the patients of $16-30$ years and $0-15$ years of age respectively. However, in the age group of 31 - 50 years and above, the positivity rate was $37 \%$ and $30 \%$ respectively (Table 1 ). Out of 163 real time PCR positive samples, the positivity rate was maximum i.e. $61 \%$ and $60 \%$ in the patients of $16-30$ years and $0-15$ years of age respectively. However, in the age group of 31-50 years and above, the positivity rate was $41 \%$ and $34 \%$ respectively, which were comparatively less (Table 1). Furthermore, in terms of gender wise variation, 115 (75\%) and 126 (77\%) were male and remaining 38 (25\%) and 37 (23\%) were female in PCR and real time PCR respectively (Table 2 ).

Our data revealed sensitivity and specificity of real time PCR for HLA-B27 positive cases were 100\% $(95 \% \mathrm{Cl}$ : $89.11-100 \%$ with p-value 0.002) and $94 \%$ (95\% Cl: $73.05-$ 91.21\% with $p$-value 0.012 ) respectively. The positive predictive value (PPV) was 93.87\% (95\% Cl: $73.01-$ $105.36 \%$ with $\mathrm{p}$-value 0.015$)$ and negative predictive value (NPV) was $100 \%$ (95\% Cl: $83.19-111.03 \%$ with $p$ value 0.101). 


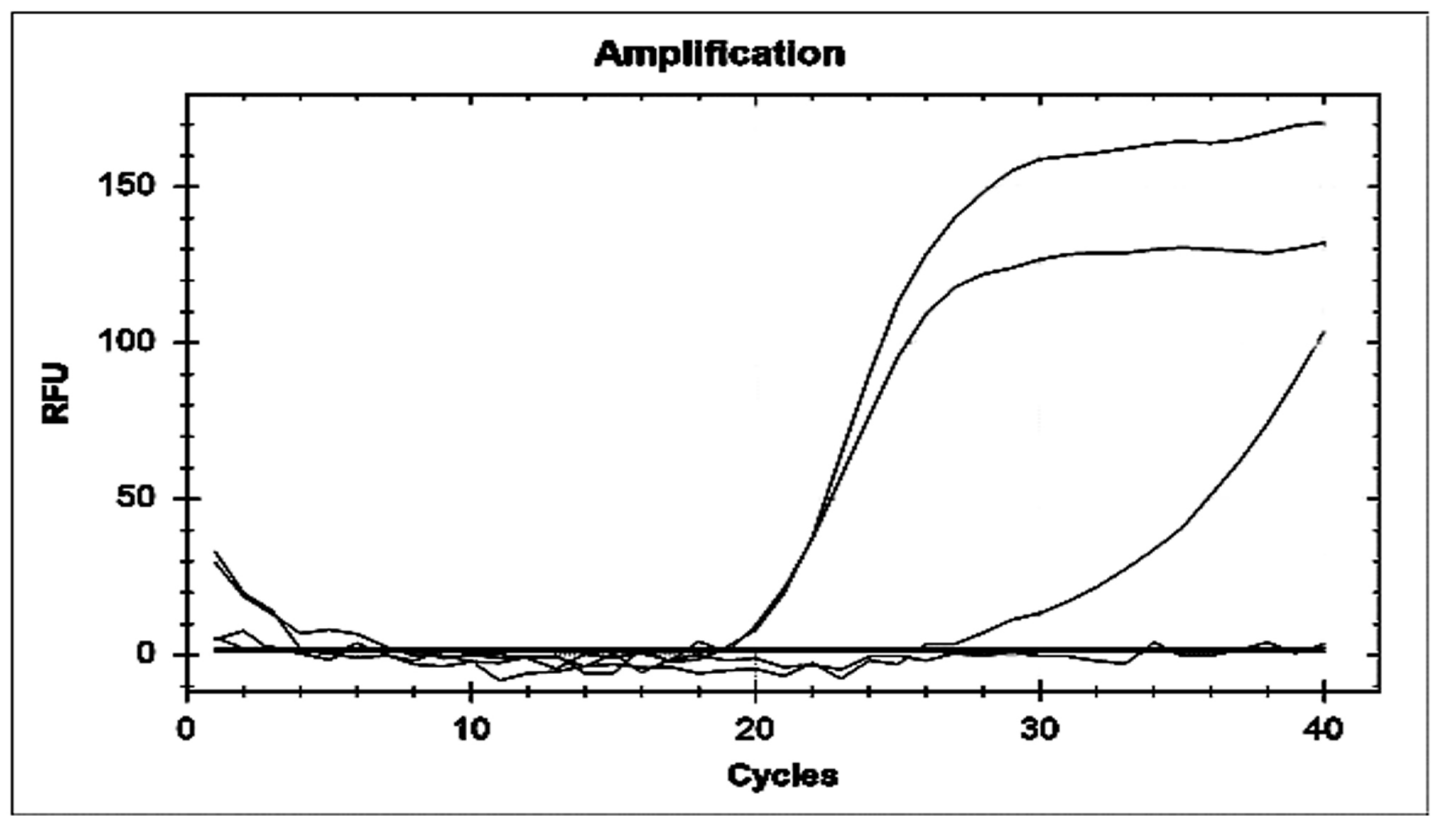

Fig. 1: A curve for each well is constructed for internal control and HLA-B27 specific probes with cycle number ( $x$-axis) vs. relative fluorescence unit ( $y$-axis). The horizontal line is set manually and results calculated for each well. Positivity

is expressed as a curve for internal control and HLA-B27 for those wells, where fluorescence levels are above the threshold

Table 1: Age wise distribution of positivity rate of the presence of HLA-B27

\begin{tabular}{cccccc}
\hline S. No. & $\begin{array}{c}\text { Age group } \\
\text { (years) }\end{array}$ & $\begin{array}{c}\text { No. of HLA-B27 positive } \\
\text { patients in PCR/ No. of } \\
\text { patients of that particular } \\
\text { age group }\end{array}$ & $\begin{array}{c}\text { Positivity rate } \\
(\%) \text { in PCR }\end{array}$ & $\begin{array}{c}\text { No. of HLA-B27 positive } \\
\text { patients in real time PCR/ } \\
\text { No. of patients of that } \\
\text { particular age group }\end{array}$ & $\begin{array}{c}\text { Positivity rate } \\
\text { (\%) in real time } \\
\text { PCR }\end{array}$ \\
\hline 1. & $0-15$ & $17 / 30$ & 57 & $18 / 30$ & 60 \\
2. & $16-30$ & $86 / 145$ & 59 & $89 / 145$ & 61 \\
3. & $31-50$ & $34 / 92$ & 37 & $38 / 92$ & 34 \\
4. & Above 51 & $16 / 53$ & 30 & $18 / 53$ & 51 \\
\end{tabular}

Table 2: Sex wise distribution of HLA-B27

\begin{tabular}{cccccc}
\hline S. No. & Sex & $\begin{array}{c}\text { No. of PCR positive } \\
\text { patients (153) }\end{array}$ & $\begin{array}{c}\text { Positivity } \\
\text { rate (\%) }\end{array}$ & $\begin{array}{c}\text { No. of real time PCR } \\
\text { positive patients (163) }\end{array}$ & Positivity rate (\%) \\
\hline 1. & Male & $115 / 153$ & 75 & $126 / 163$ & 77 \\
2. & Female & $38 / 153$ & 25 & $37 / 163$ & 23 \\
\hline
\end{tabular}




\section{DISCUSSION}

In the present study, the positivity rate of HLA-B27 in different age groups and gender-wise distribution of the HLA-B27 in patients using conventional PCR and real time PCR approach were determined. Out of 320 samples collected for the proposed study, 153 (48\%) and 163 (51\%) patients were found to be HLA-B27 positive in $P C R$ and real time PCR respectively. This result showed that the positivity rate of HLA-B27 was low in PCR in comparison with real time PCR. A negative PCR result in 10 samples was indicated by the lack of amplification with the control primers. Amplification failures may be explained by variations in small sample volume when samples are inadequately mixed.

Many factors influence the specificity of the PCR like GC content of the primer, $\mathrm{Mg}^{2+}$ ion concentration, ratio of primer to target, reaction buffer, and polymerase enzyme concentration. Sometimes samples can be contaminated with previously amplified DNA. Contamination of reagents can be minimized by preparing solutions in a separate room, which have not been exposed to amplified products, aliquoting reagents for single use only, and using dedicated consumables and equipment.

When samples were analyzed in terms of age and gender, it was found that maximum positivity rate in 1630 years followed by 0-15 years of age with approximately $3: 1$ male to female ratio. In conclusion, positive HLA-B27 status and male gender were associated with earlier age at disease onset. These results were concordance with the previous results ${ }^{[11]}$. It has been well established that $90-95 \%$ of patients with AS have HLA-B27 positive, while 5-9\% of the general population with AS may have other contributory factors ${ }^{[12]}$. In our study NPV was found to be $100 \%$ means that 157 negative patients were true negatives and may have other arthritis conditions.

Although the pathogenesis of AS is incompletely understood but is almost certainly immune mediated. The dramatic response of all aspects of the disease to therapeutic blockade of tumor necrosis factor $\alpha$ (TNF- $\alpha$ ) indicated that this cytokine plays a key role in the immunopathogenesis of AS ${ }^{[13]}$. No specific event or exogenous agent that triggers the onset of disease has been identified, although overlapping features with reactive arthritis and IBD suggest that enteric bacteria particularly Klebsiella pneumonae may play a role.
Elevated serum titers of IgA to certain enteric bacteria are common in AS patients, but no role for these antibodies in the pathogenesis of AS has been identified $[14,15]$.

It was important to establish the diagnosis of early AS before the development of irreversible deformity. Modified New York criteria are widely used as a gold standard for diagnosis. The clinical symptoms consist of a history of inflammatory back pain, limited motion of the lumbar spine in the sagittal and frontal planes, limited chest expansion, relative to standard values for age and sex and definite radiographic sacroiliitis. The presence of radiographic sacroiliitis plus any one of the other three criteria were sufficient for a diagnosis of definite AS. The presence of HLA-B27 was neither necessary nor sufficient for the diagnosis, but the HLA-B27 test can be helpful in patients with suggestive clinical findings who have not yet developed radiographic sacroiliitis. Moreover, the absence of HLA-B27 in a typical case of AS significantly increases the probability of coexistent IBD. Serological techniques such as flow cytometry, microlymphocytotoxicity (MLCT) and ELISA for testing HLA-B27 may give false negative results if HLA-B27 is down regulated or "masked". Flow cytometry is rapid and relatively inexpensive but the cross reactivity of HLAB27 with HLA-B7 decrease its specificity ${ }^{[16]}$. Identification of HLA-B27 by PCR supports the diagnosis of AS in symptomatic individuals and negative results exclude the diagnosis ${ }^{[8]}$. Real time $P C R$ is a rapid and sensitive method as compared to other diagnostic methods for the detection of HLA-B27 ${ }^{[17]}$. The main advantage was its rapidity and the possibility of automation. Moreover, identification of HLA-B27 will lead to a better understanding and treatment of the entire group of diseases collectively known as spondyloarthropathies.

\section{CONCLUSIONS}

Real time PCR detection of HLA-B27 was found to be superior to that of conventional PCR; the latter yielded false negative results. It is a fast, accurate, automated, and sensitive method for the diagnosis of AS. The main advantage of this method is that the fluorescent probe provides specificity to the reaction product and allows immediate visualization.

Real time PCR superiority over other diagnostic techniques in the diagnosis of AS makes it favorable in early diagnosis of disease and hence helps in the early treatment of patients and allays their suffering. Hence 
Real Time PCR must be used for the diagnosis of HLAB27.

\section{ACKNOWLEDGMENTS}

The authors thank to SRMS IMS Trust, Bareilly for providing the platform for such molecular diagnostic study in our laboratory.

\section{CONTRIBUTION OF AUTHORS}

Research concept- Dr. Jaspreet Kaur

Research design- Dr. Jaspreet Kaur

Supervision- Dr. Jaspreet Kaur

Materials- Dr. Jaspreet Kaur

Data collection- Dr. Jaspreet Kaur

Data analysis and Interpretation- Dr. Jaspreet Kaur

Literature search- Dr. Jaspreet Kaur

Writing article- Dr. Jaspreet Kaur

Critical review Dr. Jaswinder Singh

Article editing- Dr. Jaswinder Singh

Final approval- Dr. Jaspreet Kaur, Dr. Jaswinder Singh

\section{REFERENCES}

[1] Rudwaleit M. New approaches to diagnosis and classification of axial and peripheral spondylarthritis. Curr. Opin. Rheumatol., 2010; 22: 375-80.

[2] Lopez-Larrea C, Gonzalez-Roces S, Alvarez V. HLAB27 structure, function, and disease association. Curr. Opin. Rheumatol., 1996; 8: 296-308.

[3] Khan MA. Update on spondyloarthropathies. Ann. Intern. Med., 2002; 136: 896-907.

[4] Boyle LH, Goodall JC, Opat SS, Gaston JS. The recognition of HLA-B27 by human CD4(+) lymphocytes. J. Immunol., 2001; 167: 2619-24.

[5] Akkoc N, Khan MA. Etiopathogenic role of HLA-B27 alleles in ankylosing spondylitis. APLAR J. Rheumatol., 2005; 8: 146-53.

[6] Brionez TF, Reveille JD. The contribution of genes outside the major histocompatibility complex to susceptibility to ankylosing spondylitis. Curr. Opin. Rheumatol., 2008; 20(4): 384-91.

[7] Levering $W H$, Wind $H$, Sintnicolaas $K$, et al. Flow cytometric HLA-B27 screening: cross-reactivity patterns of commercially available anti-HLA-B27 monoclonal antibodies with other HLA-B antigens. Cytometry B. Clin. Cytom., 2003; 54(1): 28-38.
[8] Sharma N, Sharma V, Masood T, Nautiyal SC, Sailwal $S$, et al. Usage of Conventional PCR Technology for the Detection of HLA-B27 Allele: A Significant Molecular Marker of Ankylosing Spondylitis. Ind. J. Clin. Biochem., 2013; 28(2): 189-92.

[9] Seipp MT, Erali M, Wies RL, Wittwer C. HLA-B27 Typing: Evaluation of an Allele-Specific PCR Melting Assay and Two Flow Cytometric Antigen Assays. Cytometry B. Clin. Cytom., 2005; 63: 10-15.

[10]Sayer DC, Cassell HS, Christiansen FT. HLA-B*27 typing by sequence specific amplification without DNA extraction. Mol. Pathol., 1999; 52: 300-01.

[11]Xiong J, Chen J, Tu J, Ye W, Zhang Z, et al. Association of HLA-B27 status and gender with sacroiliitis in patients with ankylosing spondylitis. Pak. J. Med. Sci., 2014; 30(1): 22-27.

[12] Oostveen J, Prevo R, Den Boer J, Van de Laar M. Early detection of sacroiliitis on magnetic resonance imaging and subsequent development of sacroiliitis on plain radiography. A prospective, longitudinal study. J. Rheumatol., 1999; 26: 1953-58.

[13]Sieper J. Spondyloarthropathies in 2010: new insights into therapy-TNF blockade and beyond. Nat. Rev. Rheumatol., 2011; 7: 78-80. doi: 10.1038/nrrheum.2010.224.

[14]Harrison TR. Harrison's Principles of Internal Medicine. $16^{\text {th }}$ ed., McGraw-Hill Companies, Inc. USA: 2005: pp. 1993.

[15]Kijlstra A, Luyendijk L, Vandergaag R. Vankregten E, Linssen $A$, et al. IgG and IgA immune response against klebsiella in HLA-B27-associated anterior uveitis. Br. J. Ophthal., 1986; 70: 85-88.

[16]Neumuller J, Schwartz DWM, Dauber E. Evaluation of four monoclonal antibodies against HLA-B27 for their reliability in HLA-B27 typing with flow cytometry (FC): comparison with the classic microlymphocytotoxic test (MLCT). Cytometry, 1996; 26: 209-15. doi: 10.1002/(SICI)1097-0320(19960915) 26:3<209::AID-CYTO5>3.0.CO;2-9.

[17]Smith $S M$, Laurie $A D$, Potter HC, McGettigan BD. HLA-B27 real-time PCR using TaqMan-MGB sequence specific probes. NZ J. Med. Lab Sci., 2014; 68: 04-08. 